\title{
Periodontal Status of Patients Undergoing Hemodialysis Therapy in a Tertiary Level Hospital of Nepal
}

\section{Sweta Rajya Laxmi Rana ${ }^{1}$, and Arun Sharma ${ }^{2}$}

${ }^{1}$ Dental Department; ${ }^{2}$ Department of Medicine, Nepalese Army Institute of Health Sciences.

\begin{abstract}
Introduction: Periodontitis is a chronic inflammation of the supporting structures of the teeth. It has been shown to be associated with systemic diseases including cardiovascular and respiratory diseases, diabetes mellitus and preterm birth. Conflicting reports on the relationship of chronic renal failure patients and periodontal diseases are present in literature. No previous study has been reported in renal patients in Nepalese population. Hence this study was done to assess the oral hygiene and periodontal conditions in hemodialysis patients in a Tertiary level hospital in Nepal.

Methods: Descriptive observational study in which hemodialysis cases were assessed for periodontal parameters including Oral Hygiene- Simplified Index (OHI-S), Plaque Index (PI), Gingival Index (GI), Probing pocket depth (PPD) and clinical attachment level (CAL).

Results:A total of 30 patients (20 male, 10 female; mean age $51.06 \pm 14.37$ years) were assessed. Mean OHI-S, PI, GI, PPD and CAL were $4.02 \pm 0.89,1.93 \pm 0.27,1.57 \pm 0.28$, $2.09 \pm 0.19$ and $2.18 \pm 0.42$, respectively. The distribution of periodontitis was $10 \%$ severe, $46.66 \%$ moderate and $43.33 \%$ mild periodontitis.

Conclusions: Hemodialysis patients showed poor oral hygiene and moderate and periodontitis. Hence periodic assessment and periodontal treatment may prevent further complications in these patients.

Keywords: : chronic renal failure; gingivitis; hemodialysis; oral hygiene; periodontitis
\end{abstract}

\section{INTRODUCTION}

Chronic renal failure is a condition associated with abnormal kidney function and a progressive decline in glomerular filtration rate that necessitates treatment with renal transplantation or hemodialysis. Common etiology includes diabetes mellitus, hypertension, glomerulonephritis, polycystic kidney disease and pyelonephritis. Mortality rates in dialysis patients is $18-20 \%$ per year, mainly due to cardiovascular diseases (50\%) and infections (15\%). ${ }^{1}$ Periodontal disease is a chronic inflammatory condition broadly classified as gingivitis and periodontitis with the extension of the inflammation into the supporting structures of the teeth leading to destruction of periodontal ligament and alveolar bone and eventual tooth loss ${ }^{2}$.

Correspondence: Sweta Rajya Laxmi Rana, Dental Department, Nepalese Army Institute of Health Sciences, Kathmandu, Nepal. Email: sweta.rl.rana@gmail.com 
The role of periodontal disease in systemic conditions including cardiovascular diseases and diabetes mellitus is well known ${ }^{3-8}$ but the exact role of periodontal disease in renal disease is not clear. Periodontal disease has been found to be moderate to severe in renal failure patients 9-12 but there are few contradictory findings. ${ }^{13-14}$ Chronic inflammation like periodontitis in cardiovascular diseases may aggravate the renal condition of the patients.

Hence, there may be a direct or indirect role of periodontal disease in renal patients. This is the first known study done in Nepal to assess the periodontal status in dialysis cases.

\section{METHODS}

Patients referred to Hemodialysis Center of our hospital for dialysis for chronic kidney failure (CKD) from May 1- June 12016 were enrolled to investigate their periodontal status. The participants' age, gender, dialysis duration and systemic disease were recorded. All patients had been treated with hemodialysis for at least 3 months.

The exclusion criteria included young patients below 19 years, dentition with $<20$ teeth present, diabetes mellitus, malignancies, current smokers, clinically evident infectious diseases, surgery and antibiotics in preceding 6 months. In total, 30 out of 42 hemodialysis patients (20 male, 10 female) with mean age $51.06 \pm 14.37$ fulfilled the inclusion criteria, out of which 13 patients had (6 moderate \& 7 mild) hypertension. Signed informed consent was obtained from all the patients.

The oral and dental examination was carried out by a single trained examiner using mouth mirror, explorer and UNC-15 probe. Four parameters were assessed including oral hygiene Index-Simplified, OHI-S (Green and Vermilion) $)^{15}$ in which $16,11,26,36,13,46$ were examined. In the case of missing teeth, the adjacent teeth were examined. For Silness and Loe plaque index $(\mathrm{PI})^{15}$, Loe and Silness gingival index (GI) ${ }^{15}$, Probing Pocket Depth (PPD) and Clinical Attachment level (CAL), all teeth were examined from four sided (buccal, mesial, distal, lingual/palatal). Gingival index is a measure of the gingival inflammation. PPD was taken as the distance from the gingival margin to the base of the gingival sulcus/ periodontal pocket. Gingival recession was measured as the distance from the cementoenamel junction to the gingival margin. These scores were then added up to indirectly obtain the values for CAL.

All the subjects were categorized into three groups (Mild/No Periodontitis, Moderate Periodontitis and Severe Periodontitis) based on CAL and PPD, using the criteria proposed by the joint working group of the Centre for Disease Control and Prevention in collaboration with the American Academy of Periodontology in 2003 (Table $1^{16}$ ).

Table 1. Clinical attachment level (CAL) \& \{robing pocket depth (PD)

\begin{tabular}{|l|l|l|}
\hline Category & $\begin{array}{l}\text { Clinical } \\
\text { Attachment } \\
\text { Level (CAL) }\end{array}$ & $\begin{array}{l}\text { Probing } \\
\text { Pocket Depth } \\
\text { (PD) }\end{array}$ \\
\hline $\begin{array}{l}\text { Severe } \\
\text { Periodontitis }\end{array}$ & $\begin{array}{l}\geq 2 \\
\text { interproximal } \\
\text { sites with CAL } \\
\geq 6 \mathrm{~mm} \mathrm{(not} \\
\text { on same tooth) } \\
\text { and }\end{array}$ & $\begin{array}{l}\geq 1 \\
\text { interproximal } \\
\text { sites with PD } \geq\end{array}$ \\
$5 \mathrm{~mm}$
\end{tabular}




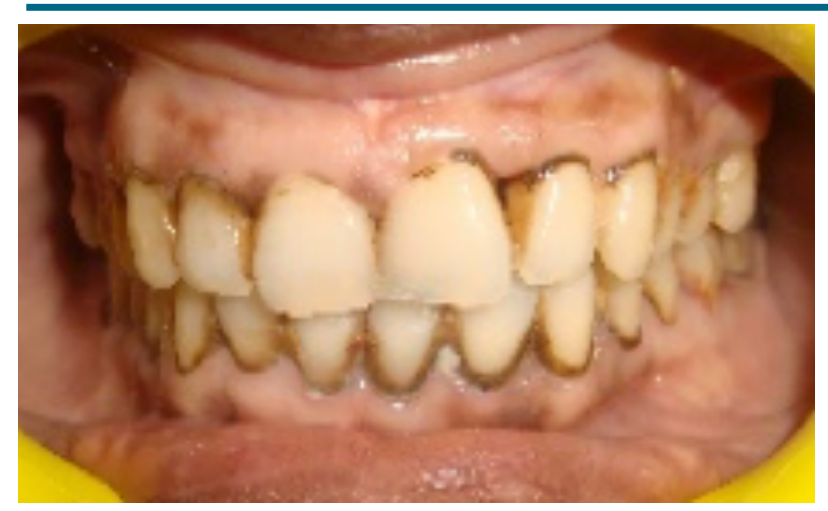

Fig.1 Generalized pallor of oral mucosa and

Table 2: Table 2. Mean of periodontal parameters. PI:Plaque index, GI:Gingival index, PPD:Probing pocket depth, CAL: Clinical attachment level

\begin{tabular}{|l|l|}
\hline Periodontal parameters & Mean \pm SD \\
\hline OHI-S & $4.02 \pm 0.89$ \\
\hline PI & $1.93 \pm 0.27$ \\
\hline GI & $1.57 \pm 0.28$ \\
\hline PPD (mm) & $2.09 \pm 0.19$ \\
\hline CAL (mm) & $2.18 \pm 0.42$ \\
\hline
\end{tabular}

\section{RESULTS}

Nearly all patients showed a generalized pallor of the oral mucosa (Fig.1). Only two patients showed mild gingival enlargement in anterior teeth.

The patients showed high OHI-S indicating poor oral hygiene with high calculus formation. The plaque index score was fair and gingival index score indicated moderate gingivitis with low levels of overall PPD and CAL. However following the CDC guideline, the active disease was calculated based on table 1 and periodontitis was seen in all cases with $46.6 \%$ showing moderate periodontitis (Table 3 ).

\section{DISCUSSION}

The present study assessed the periodontal status of the hemodialysis patients in Nepalese population due to lack of adequate knowledge
Table 3. Distribution of periodontal disease severity

\begin{tabular}{|l|r|r|}
\hline Category & Frequency & \multicolumn{2}{|c|}{ Percentage } \\
\hline $\begin{array}{l}\text { Severe } \\
\text { Periodontitis }\end{array}$ & 2 & 10 \\
\hline $\begin{array}{l}\text { Moderate } \\
\text { Periodontitis }\end{array}$ & 14 & 46.66 \\
\hline $\begin{array}{l}\text { No or Mild } \\
\text { Periodontitis }\end{array}$ & 13 & 43.33 \\
\hline Total & 30 & 100 \\
\hline
\end{tabular}

in this issue. Hemodialysis patients showed high OHI-S which signifies poor oral hygiene and moderate increase in PI and GI. Other studies ${ }^{10-11,17-18}$ have reported that high levels of OHI-S and PI levels. Oshrain et al. ${ }^{14}$ reported PI and PPD increased significantly with age, but the increase found in GI and CAL was not significant. Craig et $\mathrm{al}^{19}$ stated that mere prevalence of quiescent form of periodontal disease is not clinically as significant as active progressive disease that can impair the inflammatory state in the body. Hence case definitions proposed by CDC Working Group (Table1) was followed and this showed almost all patients had some form of periodontitis with active disease in localized areas.

Various other studies ${ }^{6,10-11,18,20}$ have reported a greater prevalence of periodontal disease in renal patients. However, contradictory findings ${ }^{13-14,21-22}$ have also been reported. OHI$\mathrm{S}$ was high in this study possibly due to high Calculus component of OHI-S. Davidovich et al ${ }^{18}$ stated that the uremic condition was positively correlated with the increase in periodontal parameters. Al Wahadni and Al Omari $^{23}$ stated that hemodialysis patients might ignore oral hygiene behaviors or other healthrelated potential problems due to spending long time in the dialysis center. Likewise, Galili et al. ${ }^{24}$ stated these patients neglected oral health and 
showed poor compliance to dental treatment as they might be depressed.

The patients in this study had a shorter duration of dialysis (6 months- 3 years) with most cases with treatment duration of less than a year. Torkzaban et al. ${ }^{25}$ did not find any relationship between dialysis duration and periodontal indices, which probably is due to the shorter average duration of dialysis (1.3 years). Jenabian et $\mathrm{al}^{9}$ reported a higher incidence of periodontal disease with longer duration of dialysis.

In this study, patients had poor oral hygiene with moderate gingivitis. Bleeding on probing is an objective measure of gingivitis but in these cases generalized pallor was seen with most of them showing anemia (Hb levels 6.1-9 gm/dL). Naugle et $\mathrm{al}^{17}$ reported high bleeding on probing in adolescent patients on dialysis but they did not specify the proportion of patients on peritoneal dialysis versus hemodialysis. High dose heparin in anemic patients can cause increased bleeding but patients in this study were on low dose heparin and were found to have moderate gingivitis even with poor oral hygiene. A study reported that the uremic state in the hemodialysis patients may suppress inflammatory reactions in the tissues, which would result in lower chances of detection of gingivitis. ${ }^{26}$ Insignificant change of GI may be due to suppression of immune system. Uremia has been reported to impair T \& B-lymphocyte function ${ }^{27}$ but this was not found to be so in yet another study. ${ }^{28}$

Periodontitis is known to be a covert source of systemic inflammation with $\alpha 2$ macroglobulin, $\alpha 1$ antitrypsin and C-reactive protein (CRP) ${ }^{11,29}$. Beck et $\mathrm{al}^{30}$ stated the cardiovascular risk were 1.5, 1.9, 2.8 for bone loss, total Chronic heart disease (CHD), fatal CHD and stroke by increasing endotoxins burden and cytokines like
Thromboxane $\alpha 2$, Interleukin-2 $\beta$, PGE2, TNF$\alpha$. Grubbs et $\mathrm{al}^{31}$ in NHANES US National survey found moderate and severe periodontitis were $5.3 \%$ and $10.6 \%$ and that periodontal disease had two-fold risk of Chronic kidney disease. Independent associations between poor dental health and cardiovascular disease in maintenance hemodialysis patients, and between advanced periodontitis and left ventricular hypertrophy in kidney transplant recipients have been shown ${ }^{32}$.

Furthermore, there have been studies that show periodontal therapy has beneficial effect on some cardiovascular risk factors in otherwise healthy patients with periodontitis with reduction in systemic markers and cholesterol levels and in blood pressure. A three-fold decrease in CRP and ESR and a rise in Hemoglobin levels in Hemodialysis patients were reported to occur after 6 weeks of periodontal therapy ${ }^{9,33}$ which is in accordance with a review by Ariyamuthu et $\mathrm{al}^{34}$ in 2013.

The limitations of the present study was that the study was done in a single centre with a small sample since adolescents, diabetics, current smokers and patients under antibiotics in previous 6 months were excluded. There may be confounding factors like anemia, stress, socioeconomic and behavioral factors. Controls were not used for this study since there is always possibility of bias in a non-blinded study. Further multi-centric longitudinal studies should be done in patients with long-term therapy. A meta-analysis by Paraskevas et al in $2008^{35}$ has reported that the issue of poor oral health status in CKD patients apparently deserves a higher awareness of the problem, and increased attention, and indicates the need for a closer collaboration between primary care physicians, nephrologists and dentists. 


\section{CONCLUSION}

The hemodialysis patients showed high levels of calculus formation, poor oral hygiene and moderate periodontal disease. There may be a need to assess, monitor and treat the periodontal condition of these patients to prevent further progression of periodontal disease and improve the overall health of the patient.

\section{REFERENCES}

1. Lim KD, Chertow DM. Dialysis in the Treatment of Renal Failure, In: Harrison TR. Harrison's Principles of Internal Medicine, 17th ed. USA: McGraw Hill 2001; volume II, Chap. 275, p p 1772 , IB SN 978-0-07-14769-5

2. Armitage G.C. Development of a classification system for periodontal diseases and conditions. Ann Periodontol. 1999;4:1:1-6. DOI:10.1902/annals. 1999.4.1.1

3. Scannapieco FA. Systemic effects of periodontal diseases. Dent Clin North Am. 2005;49:533-50. DOI:10.1016/j.cden. 2005.03.002

4. Spahr A et al. Periodontal infections and coronary heart disease: role of periodontal bacteria and importance of total pathogen burden in the Coronary Event and Periodontal Disease (CORODONT) study. Arch Intern Med. 2006; 166:554-59. DOI: 10.1001/archinte.166.5.554

5. Desvarieux $M$ et al. Relationship between periodontal disease, tooth loss, and carotid artery plaque: the Oral Infections and Vascular Disease Epidemiology Study (INVEST). Stroke. 2003;34:2120-25. DOI: 10.1161/01.STR.0000085086.50957.22

6. Rahmati MA, Craig RG, Homel P, Kaysen G, Levin NW. Serum markers of periodontal disease status and inflammation in hemodialysis patients. Am J Kidney Dis. 2002;40:983-89. DOI:10.1053/ajkd. $\underline{2002.36330}$

7. Kshirsagar AV et al. Periodontal disease is associated with renal insufficiency in the Atherosclerosis Risk in Communities
(ARIC) study. Am J Kidney Dis. 2005;45: 650-57. PMID: 15806467

8. Casanova L, Hughes FJ, Preshaw PM. Diabetes and periodontal disease: a two-way relationship, British Dental Journal. 2014;217:433-37. DOI: 10.1038/sj.bdj. 2014.907

9. Jenabian N, Ghazi Mirsaeed AM, Ehsani H, Kiakojori A. Periodontal status of patient's underwent hemodialysis therapy. Caspian Journal of Internal Medicine. 2013;4(2): 658-661. PMCID:PMC3755829

10. Chen LP, Chiang CK, Chan CP, Hung KY, Huang CS. Does periodontitis reflect inflammation and malnutrition status in hemodialysis patients? Am J Kidney. Dis 2006;47:815-22. DOI: $10.1053 /$ j.ajkd. 2006.01.018

11. Joseph R, Krishnan R, Narayan V. Higher prevalence of periodontal diseases among patients with predialytic renal disease, Braz $J$ Oral Sci. 2009:8:1:14-18

12. Ismail $\mathrm{G}$ et al. Periodontal disease: A Covert Source of inflammation in Chronic Kidney Disease Patients, International Journal of Nephrology. 2013: Article ID 515796, p.1-6. http://dx.doi.org/10.1155/2013/515796

13. Mortazavi $\mathrm{H}$ et al. Evaluation of the Dental and periodontal status of haemodialysis subjects and its comparison with that of healthy people. Sci J Hamedan Univ Med Sci. 2010;17:10-6.

14. Oshrain HI, Mendre S, Mandel ID. Periodontal status of patients with reduced immunocapacity. J periodontal 1979; 50: 185-8. DOI: 10.1902/jop.1979.50.4.185

15. Spolsky VW. Epidemiology of gingival and periodontal disease. In: Newman MG, Carranza FA. Clinical Periodontology, $8^{\text {th }}$ ed. India: Hartcourt Asia:1996. p. 64-8.

16. Page RC, Eke PI. Case definitions for use in population-based surveillance of periodontitis. J Periodontol. 2007;78:1387-99. DOI: 10.1902/jop. 2007.060264

17. Naugle $\mathrm{K}$ et al. The oral health status of individuals on renal dialysis. Annal 
Periodontal Status During Hemodialysis; Rana SR

Periodont. 1998;3:197-205. DOI:10.1902/ annals.1998.3.1.197

18. Davidovich E, Davidovits M, Eielman E, Schwartz Z, Bimstein E. Pathophysiology, therapy, and oral implications of renal failure in children and adolescents: an update. Pediatr Dent. 2005;27:98-106. PMID: 15926286

19. Craig RG, Kotanko P, Kamer AR, Levin NW. Periodontal diseases-a modifiable source of systemic inflammation for the endstage renal disease patient on haemodialysis therapy? Nephrol Dial Transplant. 2007;22:312-15. DOI: 10.1093/ndt/gfl604

20. Borawski J, Wilczyńska-Borawska $\mathrm{M}$, Stokowska W, Myśliwiec M. The periodontal status of pre-dialysis chronic kidney disease and maintenance dialysis patients. Nephrol Dial Transplant. 2007;22:457-64. DOI: $10.1093 / \mathrm{ndt} / \mathrm{gfl} 676$

21. Marakoglu IK, Gursoy KD, Demirer S, Sezer H. Periodontal status of chronic renal failure patients receiving hemodialysis. Yonsei Med J. 2003;44:648-52.

22. Bayraktar G et al. Dental and periodontal findings in hemodialysis patients. Oral Diseases. 2007;13:393-7. DOI:10.1111/j. 1601-0825.2006.01297.x

23. Al-Wahadni A, Al-Omari MA. Dental diseases in a Jordanian population on renal dialysis. Quintessence Int. 2003;34:343-7. PMID: 12795352

24. Galili D, Kaufman E, Leviner E, Lowental U. The attitude of chronic hemodialysis patients toward dental treatment. Oral Surg Oral Med Oral Pathol. 1983;56:602-4. PMID: 6581457

25. Torkzaban P, Arabi R, Kadkhodazadeh M, Moradi J, Khoshhal M. Periodontal Status in Patients Undergoing Hemodialysis. Dent J Hamedan 2009; 1: 7-10.

26. Kerr AR. Update on renal disease for the dental practitioner. Oral Surg Oral Med Oral Pathol Oral Radiol Endod. 2001;92:9-16. DOI: $10.1067 /$ moe. 2001.115976

27. Girndt $\mathrm{M}$ et al, Molecular aspects of T- and B- cell function in Uraemia, Kidney
International. 2001:59:78:S206-11. DOI: 10.1046/j.1523-1755.2001.59780206.x

28. Kitsou VK, Konstantinidis A, Siamopoulos KC. Chronic renal failure and periodontal disease. Ren Fail 2000; 22: 307-18. PMID: 10843241

29. Loos BG, Craandijk J, Hoek FJ, Wertheimvan Dillen PM, van der Velden U. Elevation of systemic markers related to cardiovascular diseases in the peripheral blood of periodontitis patients. J Periodontol. 2000;71(10):1528-34. DOI:10.1902/jop. 2000.71.10.1528

30. Beck $\mathrm{J}$ et al. Periodontal disease and cardiovascular disease. J Periodontol. 1996;67(10 suppl):1123-37. DOI:10.1902/ jop.1996.67.10s.1123

31. Grubbs V et al. Vulnerable populations and the association between periodontal and chronic kidney disease. Clin J Am Soc Nephrol. 2011;6:711-17. doi: 10.2215/CJN. $\underline{08270910}$

32. Wilczyn'ska-Borawska M, Borawski J, Stokowska W. Risk factors of tooth loss in maintenance hemodialysis patients. Dent Med Probl. 2004;41:751-56.

33. D' Aiuto $F$ et al. Short-term effects of intensive periodontal therapy on serum inflammatory markers, Journal of dental Research. 2004:83:2:156-60.

34. Ariyamuthu VK, Nolph KD, Ringdahl BE. Periodontal disease in chronic kidney disease and End-stage renal disease patients: A review, Cardiorenal Med. 2013;3:71-78. DOI: $10.1159 / 000350046$

35. Paraskevas S, Huizinga JD, Loos BG. A systematic review and meta-analysis on $\mathrm{C}$ reactive protein in relation to periodontits, $J$ Clin Periodontol. 2008;35:227-90. DOI: 10.1111/j.1600-051X.2007.01173.X 